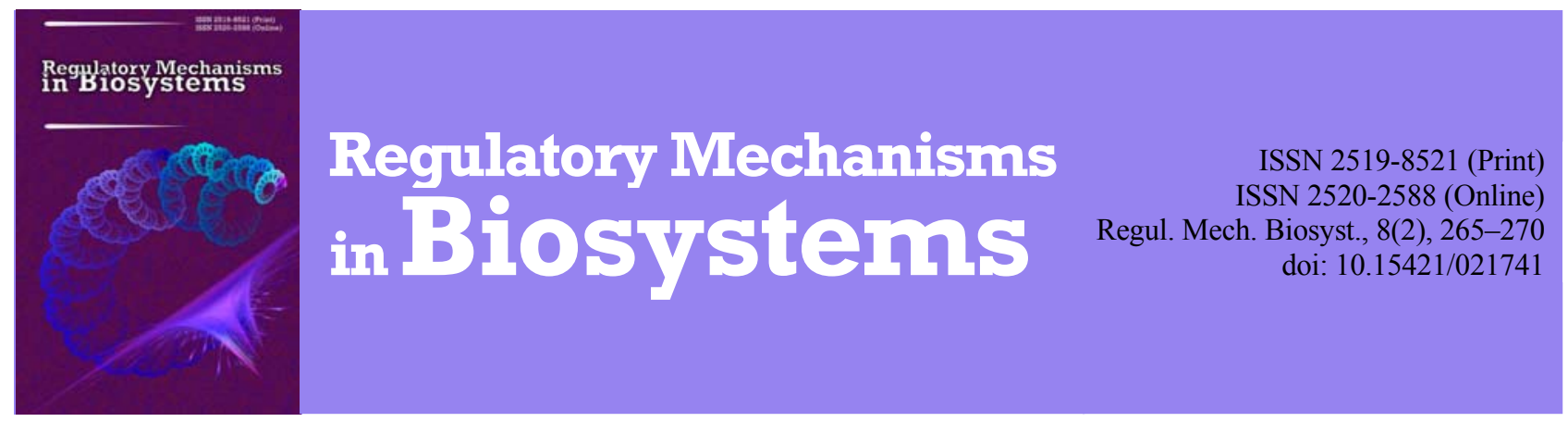

\title{
Morphofunctional characteristics of hepatocytes after exposure to intermittent normobaric hypoxia in normotensive and hypertensive rats
}

\author{
R. Yanko, V. Berezovskii, E. Chaka, M. Levashov, L. Plotnikova, I. Litovka \\ A. A. Bogomolets Institute of Physiology of NAS of Ukraine, Kiev, Ukraine
}

Article info

Received 24.03.2017

Received in revised form 20.04.2017

Accepted 23.04.2017

A. A. Bogomolets Institute of Physiology of NAS of Ukraine,

Bogomolets Str., 4

Kiev, 01024, Ukraine

Tel.: +38-044-256-24-77

E-mail:biolag@ukrnet
Yanko, R., Berezovskii, V., Chaka, E., Levashov, M., Plotnikova, L., \& Litovka, I. (2017). Morphofunctional characteristics of hepatocytes after exposure to intermittent normobaric hypoxia in normotensive and hypertensive rats. Regulatory Mechanisms in Biosystems, 8(2), 265-270. doi:10.15421/021741

There are only few studies in which the effect of intermittent normobaric hypoxia on the liver status in animals and people with arterial hypertension has been investigated. That's why it's necessary to carry out these studies in animals with high blood pressure. The purpose of this work was to carry out comparative studies of the effect of dosed intermittent normobaric hypoxia on the morphofunctional state of hepatocytes of normotensive (line Wistar) and spontaneously hypertensive (line SHR) rats, age 4 months. The experimental rats were daily exposed to hypoxic gas mixture (12\% oxygen in nitrogen) in intermittent mode: 15 minutes deoxygenation / 15 minutes reoxygenation for 2 hours. The duration of the experiment was 28 days. Histological, morphometric and biochemical research methods were used. The histological preparations were made by the standard methods. The slides were photographed using a digital camera on the microscope "Nikon" (Japan). The morphometric analysis was performed on digital images using the computer program "Image J". The activity of cytochrome oxidase and succinate dehydrogenase enzymes in a suspension of hepatocytes mitochondria was determined by the method of R. S. Krivchenkov. An increase was observed in the size of hepatocytes and their nucleus, in the number of binuclear hepatocytes and nucleolus in the liver of both experimental lines of animals after exposure to intermittent normobaric hypoxia. The distance between adjacent nuclei of hepatocytes decreased. Cytochrome oxidase activity in a suspension of mitochondria increased. These morphological changes took place in the liver parenchyma of the both experimental lines of rats. But they were more pronounced in the liver of rats of the Wistar line than in the SHR line. Our data indicated that dosed normobaric hypoxia had a one-way, stimulating effect on the morphofunctional activity of hepatocytes, but the severity of this effect in rats of different lines was not the same. The obtained data can have not only theoretical value, but also be of some practical interest when using intermittent normobaric hypoxia for medical and health purposes in patients with impaired liver function and arterial hypertension.

Keywords: intermittent normobaric hypoxia; liver parenchyma; morphometry; arterial hypertension; cytochrome oxidase

\section{Морфофункциональная характеристика гепатоцитов нормотензивных и гипертензивных крыс после воздействия прерывистой нормобарической гипоксии}

\author{
Р. В. Янко, В. А. Березовский, Е. Г. Чака, М. И. Левашов, Л. Н. Плотникова, И. Г. Литовка
}

Институт физиологии имени А. А. Богомольцฺа НАН Украиньл, Киев, Украина

Исследовали влияние дозированной нормобарической гипоксии (12\% кислорода в азоте) в прерывистом режиме (15 мин. деоксигенация, 15 мин. реоксигенация в течение 2 часов ежедневно на протяжении 28 суток) на морфофункциональное состояние гепатоцитов нормотензивных (линия Wistar) и спонтанно-гипертензивных (линия SHR) молодых крыс-самцов. Использованы гистологические, морфометрические и биохимические методы исследования. Гистологические препараты изготавливали по стандартной методике. На цифровых изображениях препаратов осуществляли морфометрию с помощью компьютерной программы Image J. В печени подопытных животных обеих линий после воздействия прерывистой нормобарической гипоксии выявлено увеличение размеров гепатоцитов и их ядер, количества двуядерных клеток и ядрышек в ядрах, уменьшение расстояния между ядрами смежных гепатоцитов, а также возрастание активности цитохромоксидазы в суспензии митохондрий. B паренхиме печени крыс линии Wistar эти морфофункциональные изменения были выражены в большей степени, чем в печени крыс линии SHR. Полученные данные свидетельствуют о том, что прерывистая нормобарическая гипоксия оказывает однонаправленный, стимулирующий эффект на морфофункциональную активность гепатоцитов, но степень выраженности данного эффекта у крыс разных линий не одинакова. Результаты могут не только иметь 
теоретическое значение, но и представлять определенный практический интерес при использовании прерывистой нормобарической гипоксии в лечебных и оздоровительных целях у больных с нарушением функций печени.

Ключевые слова: прерывистая нормобарическая гипоксия; печень; морфометрия; артериальная гипертензия; цитохромоксидаза

\section{Введение}

Вопрос о механизмах и закономерностях адаптации организма к изменениям важнейших факторов внешней среды остается одной из актуальных проблем современной биологии и медицины. Важность данной проблемы для практической медицины обусловлена также тем, что адаптационные реакции составляют основу естественной профилактики болезней и сохранения здоровья человека (Dasgupta, 2016). Согласно широко известной концепции о перекрестной адаптации, возникновение устойчивости организма к одному экстремальному фактору может повышать его устойчивость к иным неблагоприятным воздействиям. Продолжительное воздействие дозированной умеренной гипоксии на человека и животных активирует комплекс защитно-приспособительных механизмов, способствующих повышению неспецифической резистентности организма (Chizhov and Billo, 2007; Berezovsky, 2012).

Функциональное состояние печени является одним из индикаторов гомеостазиса организма в целом. Печень обладает высокой чувствительностью к недостатку кислорода, что обусловлено высокой интенсивностью протекающих в ней метаболических процессов (Rui, 2014). Проблема влияния гипоксии на состояние печени настолько обширна, сложна и многогранна, что многие ее аспекты остаются не решенными и сохраняют свою актуальность до настоящего времени. На протяжении длительного времени исследовали, главным образом, физиологические механизмы адаптации к гипоксии, а также ее роль в патогенезе различных заболеваний. В частности, изучена роль респираторной, циркуляторной, тканевой, гемической гипоксии в патогенезе тяжелых нарушений функции печени (Feng et al., 2010; Aron-Wisnewsky et al., 2011; da Rosa et al., 2012). Большинство этих исследований выполнено в условиях острого и хронического воздействия гипобарической гипоксии различной степени выраженности и продолжительности (Siques et al., 2013; Tian et al., 2016). Пониженное атмосферное давление усугубляет негативные последствия воздействия гипоксии на организм человека. Со времен Н. Н. Сиротинина (Sirotinin, 1949) гипоксия стала рассматриваться не только как повреждающий фактор, а и как немедикаментозный метод повышения защитных приспособительных возможностей организма в лечебно-профилактической практике. Профессором Стрелковым и соавторами разработаны основы использования гипоксических газовых смесей для этих целей в виде прерывистой нормобарической гипоксии (Karash, 1988). Профессором В. А. Березовским (Berezovskiy, 2012) разработана концепция саногенной гипоксии. В соответствии с данной концепцией гипоксия, соответствующая высоте 1,5-3,0 тыс. м над уровнем моря (12$17 \%$ кислорода), оказывает лечебное и оздоравливающее действие на организм человека. Воздействие гипоксическими газовыми смесями, соответствующими данной высоте, в прерывистом режиме в условиях нормального атмосферного давления, с одной стороны, исключает неблагоприятные последствия гипобарии и гипоксии, а с другой - потенцирует саногенные эффекты последней. В настоящее время прерывистая нормобарическая гипоксия все более широко используется в клинической практике для лечения и профилактики ряда заболеваний сердечно-сосудистой, дыхательной, эндокринной, пищеварительной, иммунной и других систем организма (Mekjavic et al., 2012; Serebrovskaya and Xi, 2015, 2016; Lutz Schega et al., 2016). Механизмы саногенного действия нормобарической гипоксии требуют дальнейшего изучения и уточнения. Исследования, в которых бы описывалось влияние прерывистой нормобарической гипоксии саногенного уровня на морфофункциональное состояние гепатоцитов, единичны (Lebkova et al., 1999; Yanko, 2011).
Данные литературы о влиянии гипоксических газовых смесей на функциональное состояние печени неоднозначны. Это можно связать, с одной стороны, с существующим многообразием методических подходов, используемых для моделирования гипоксических состояний, а с другой - с индивидуальными, внутри- и межвидовыми различиями устойчивости живых существ к гипоксии (Savransky et al. 2007; Berezovs'kyi et al., 2012). Большинство исследований, посвященных влиянию прерывистой нормобарической гипоксии (ПНГ) на состояние паренхимы печени, проведено на крысах линии Wistar (Yanko, 2011; Simoes et al., 2013). Работ, в которых бы исследовалось влияние ПНГ на состояние печени у животных и людей с артериальной гипертензией, нами не обнаружено. Можно полагать, что воздействие ПНГ на людей или животных с повышенным артериальным давлением может оказать как прямое, так и опосредованное влияние на состояние паренхимы печени. С другой стороны, длительная артериальная гипертензия также может привести к нарушению морфофункционального состояния печени и изменить тем самым характер адаптивных перестроек, характерных для воздействия ПНГ. Широкое распространение сочетанной патологии органов пищеварения и кровообращения требует комплексного подхода не только к лечению таких больных, но и к усовершенствованию существующих методов ранней диагностики и профилактики данных заболеваний. Это обуславливает необходимость проведения исследований на животных с повышенным артериальным давлением.

Цель статьи - сравнить влияние дозированной прерывистой нормобарической гипоксии саногенного уровня на морфофункциональное состояния гепатоцитов нормо- и гипертензивных крыс.

\section{Материал и методы исследований}

Исследование проведено на 48 нормотензивных (линия Wistar) и спонтанно-гипертензивных (линия SHR) крысах-самцах. Животные взяты из питомника вивария Института физиологии имени А. А. Богомольца НАНУ. Возраст крыс на конец эксперимента составлял 4 месяца, масса $-270 \pm 10$ г. Крысы находились в унифицированных условиях на стандартном рационе питания. Артериальное давление у крыс определяли в условиях вивария неинвазивным методом на хвостовой артерии. Все измерения проводили с помощью сфигмоманометра (S-2 SHE, Германия). В эксперимент брали крыс линии SHR с систолическим давлением не ниже 145 мм рт. ст.

Животные были разделены на четыре группы: I и III контрольные крысы линии Wistar и SHR соответственно, II и IV - подопытные крысы линии Wistar и SHR. Крысы подопытных групп ежедневно дышали гипоксической газовой смесью. Для проведения сеанса гипоксического воздействия крыс размещали в герметичной камере, в которую с мембранного газоразделительного элемента подавали гипоксическую газовую смесь (12\% кислорода в азоте) в прерывистом режиме: 15 мин. деоксигенация, 15 мин. реоксигенация в течение 2 часов. Все оставшееся время суток (22 часа) крысы находились в клетке и дышали атмосферным воздухом. Общая продолжительность эксперимента составляла 28 суток. Крыс выводили из эксперимента путем декапитации под эфирным наркозом. Все протоколы исследований соответствовали положениям Конвенции по биоэтике Совета Европы (1997), Хельсинской декларации Всемирной медицинской ассоциации (1996), Европейской конвенции о защите позвоночных животных, которые используются для экспериментальных и других научных целей (Страсбург, 1985), общим этичным принципам экспериментов на животных, принятым Первым национальным конгрессом Украины по биоэтике 
(2001), а также Комитетом по биомедицинской этике Института физиологии имени А. А. Богомольца НАНУ.

Для морфометрических исследований из ткани печени готовили гистологические препараты по стандартной методике: фиксировали в жидкости Буэна, обезвоживали в спиртах возрастающей концентрации и диоксане, заливали в парафин. Срезы окрашивали гематоксилином Бемера и эозином, а для выявления элементов соединительной ткани - методом Ван-Гизона и Массона (Korzhevskij and Giljarov, 2010). При использовании цифровой камеры микропрепараты фотографировали на микроскопе «Nicon» (Япония). На цифровых изображениях препаратов осуществляли морфометрию с помощью компьютерной программы «Image J».

На гистологических срезах печени подсчитывали количество гепатоцитов, ядрышек (на 100 ядер), измеряли средний диаметр, площадь поперечного сечения гепатоцитов, их ядер и цитоплазмы, расстояние между ядрами смежных клеток. Подсчет количества гепатоцитов проводили в 10 полях зрения микроскопа, а измерения площади осуществляли для каждой клетки с подсчетом среднего значения по отношению к 100 клеткам. Все морфометрические измерения гепатоцитов проводили при увеличении микроскопа в 400 раз (Nikonenko, 2013).

Активность ферментов энергетического метаболизма - цитохромоксидазы и сукцинатдегидрогеназы в суспензии митохондрий гепатоцитов определяли методом Krivchenkova (1977).
Статистическую обработку осуществляли методами вариационной статистики с помощью компьютерной программы Statistica 6.0. Нормальность распределения цифровых массивов проверяли используя критерий Пирсона. При нормальности распределения для оценки коэффициента различий достоверности разницы между контрольными и подопытными группами использовали t-критерий Стьюдента. Различия считали достоверными при $\mathrm{P}<0,05$.

\section{Результаты}

После воздействия ПНГ у крыс обеих линий паренхима печени сохраняла физиологическую структуру. Печеночные пластинки имели радиальную направленность, центральные вены, ветви воротной вены, синусоиды оставались умеренно кровенаполненными. Междольковая соединительная ткань была выражена слабо. В центральных венах местами наблюдали скопления эритроцитов. Гепатоциты среднего и большого размера имели хорошо выраженную мембрану. Ядра округлой формы, фиолетовой окраски, расположены в центре клетки. Ядерная мембрана сохранена и имела четкие очертания. Окраска цитоплазмы была умеренно интенсивной, равномерно розовой. Иногда в ней встречались вакуоли или включения. Ядрышки округлой формы, среднего размера (рис. 1).
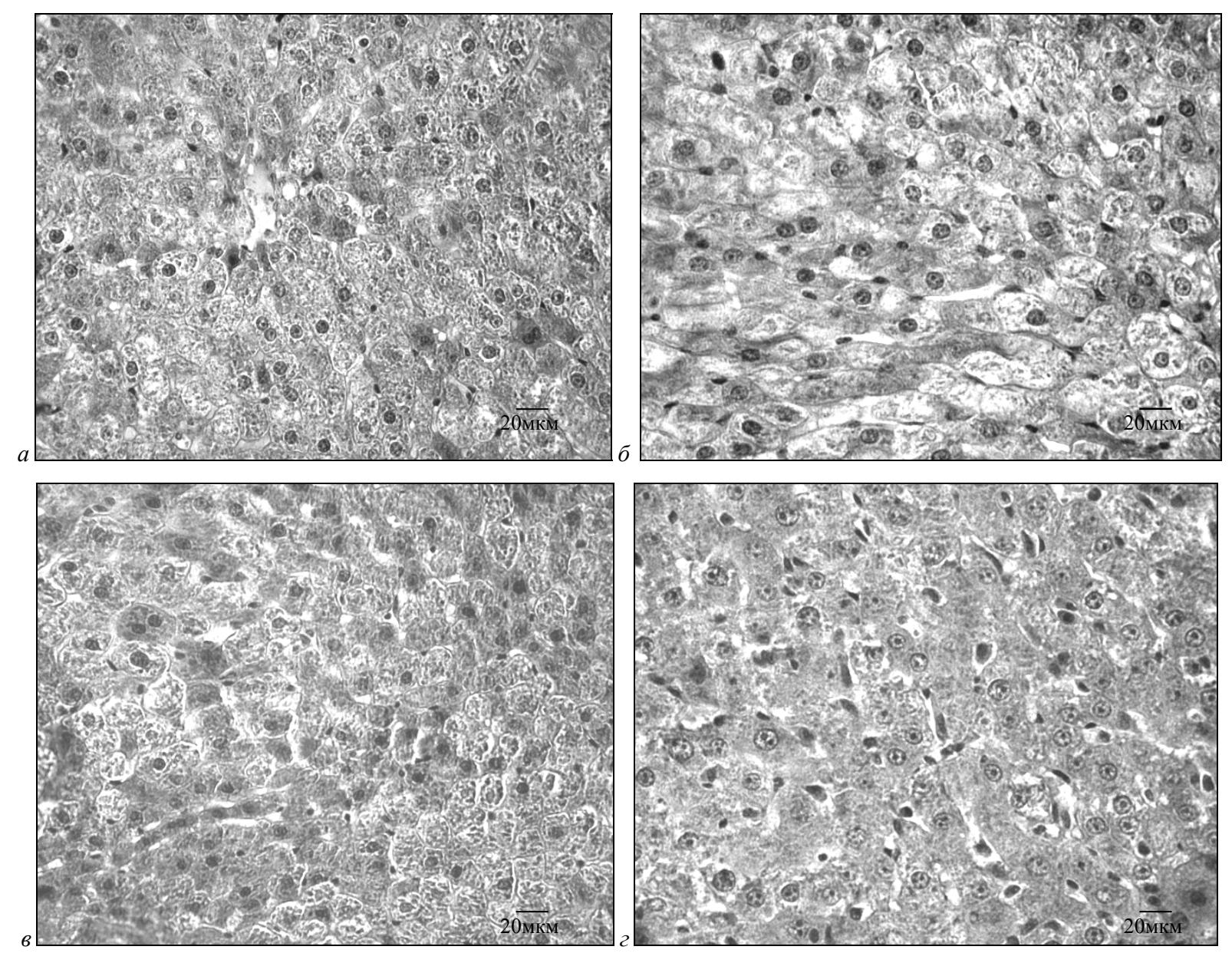

Pис. 1. Микрофотография печени контрольных ( $a$ - линия Wistar, 8 - линия SHR) и подопытных ( $\sigma$ - линия Wistar, 2 - линия SHR) крыс: окраска гематоксилином Бемера и эозином

Сравнительные исследования структуры паренхимы печени контрольных крыс разных линий позволили выявить определенные различия. Гепатоциты крыс линии SHR имели достоверно большие размеры: площадь поперечного сечения клетки, ее ядра и цитоплазмы превышали на $22 \%, 34 \%$ и $39 \%$ соответствующие показатели крыс линии Wistar. Кроме того, у животных этой линии в поле зрения наблюдали большее количество одноядерных (на $6 \%$ ) и двуядерных (на $13 \%$, Р < 0,05$)$ гепатоцитов (табл.).

У крыс обеих линий, подвергавшихся воздействию прерывистой гипоксии, отмечали достоверно больший размер гепатоцитов. У подопытных животных линии Wistar средний диаметр гепатоцитов был больше на $12 \%$, а площадь поперечного сечения клеток, их ядер и цитоплазмы - на $33 \%$, 48\% и $51 \%$ 
соответственно, чем у контрольных крыс. Ядерно-цитоплазматическое соотношение увеличилось на $12 \%(\mathrm{P}<0,05)$. У подопытных крыс линии SHR наблюдали менее значительное увеличение размеров гепатоцитов: среднего диметра - на 5\%, площади клетки - на $7 \%$, ее ядра - на $28 \%(\mathrm{P}<0,05)$ и цитоплазмы на $3 \%$ по сравнению с контролем. Ядерно-цитоплазматическое соотношение достоверно возросло на $26 \%$ (табл.).
После воздействия ПНГ в ядрах гепатоцитов подопытных крыс обеих линий количество ядрышек было на $11 \%$ (линия Wistar) и 23\% (линия SHR) больше, чем у контрольных. При этом ядрышко-ядерное соотношение, наоборот, уменьшилось на $24 \%(\mathrm{P}<0,05)$ и $4 \%$ соответственно за счет более существенного увеличения площади ядер гепатоцитов по сравнению с суммарной площадью ядрышек (табл.).

\section{Таблица}

Морфометрические показатели функционального состояния гепатоцитов контрольных и подопытных крыс разных линий $(\mathrm{M} \pm \mathrm{m}, \mathrm{n}=12)$

\begin{tabular}{|c|c|c|c|c|}
\hline \multirow{2}{*}{ Показатели } & \multicolumn{2}{|c|}{ Линия Wistar } & \multicolumn{2}{|c|}{ Линия SHR } \\
\hline & контроль & гипоксия & контроль & гипоксия \\
\hline \multirow{2}{*}{\multicolumn{5}{|c|}{ Площадь, мкм²: }} \\
\hline & & & & \\
\hline гепатоцита & $340,7 \pm 15,20$ & $454,6 \pm 18,01^{*}$ & $414,6 \pm 17,10^{* *}$ & $444,0 \pm 18,70$ \\
\hline ядра & $49,1 \pm 1,64$ & $72,7 \pm 3,99^{*}$ & $65,9 \pm 1,48^{* *}$ & $84,5 \pm 2,47^{*}$ \\
\hline цитоплазмы & $291,6 \pm 12,91$ & $381,9 \pm 22,20^{*}$ & $348,7 \pm 13,50^{* *}$ & $359,5 \pm 17,0$ \\
\hline Ядерно-цитоплазматическое соотношение & $0,17 \pm 0,006$ & $0,19 \pm 0,004^{*}$ & $0,19 \pm 0,009$ & $0,24 \pm 0,008^{*}$ \\
\hline \multicolumn{5}{|l|}{ Количество гепатоцитов (в поле зрения при х 400 раз): } \\
\hline общее & $125,6 \pm 2,90$ & $137,5 \pm 2,86$ & $133,3 \pm 6,05$ & $130,6 \pm 3,95$ \\
\hline одноядерных & $122,5 \pm 3,11$ & $133,7 \pm 3,81$ & $129,8 \pm 6,13$ & $126,8 \pm 3,86$ \\
\hline двуядерных & $3,1 \pm 0,11$ & $3,8 \pm 0,12^{*}$ & $3,5 \pm 0,10^{* *}$ & $3,8 \pm 0,27$ \\
\hline Соотношение двуядерные/одноядерные гепатоциты & $0,025 \pm 0,001$ & $0,028 \pm 0,001 *$ & $0,027 \pm 0,001$ & $0,030 \pm 0,001$ \\
\hline Количество ядрьшек в ядре & $1,69 \pm 0,04$ & $1,87 \pm 0,05^{*}$ & $1,64 \pm 0,05$ & $2,02 \pm 0,05^{*}$ \\
\hline Ядрышко-ядерное соотношение & $0,034 \pm 0,001$ & $0,026 \pm 0,001^{*}$ & $0,025 \pm 0,002 * *$ & $0,024 \pm 0,001$ \\
\hline Расстояние между ядрами смежных гепатоцитов & $11,4 \pm 0,38$ & $9,85 \pm 0,29 *$ & $11,7 \pm 0,35$ & $9,9 \pm 0,27^{*}$ \\
\hline
\end{tabular}

Примечание: * - $\mathrm{P}<0,05$ по сравнению с контролем; ** - $\mathrm{P}<0,05$ по сравнению с контролем линии Wistar.

В печени подопытных животных линии Wistar выявлена тенденция к увеличению (на 9\%) как общего количества, так и количества одноядерных гепатоцитов. Количество одноядерных гепатоцитов у подопытных животных линии SHR не отличалось от контрольных значений. После воздействия ПНГ количество двуядерных гепатоцитов у крыс линии Wistar и SHR было больше на $23 \%(\mathrm{P}<0,05)$ и $9 \%$ соответственно, чем в контроле (табл.).

B паренхиме печени подопытных крыс как линии Wistar, так и линии SHR выявлено достоверное уменьшение расстояния между ядрами смежных гепатоцитов на $11 \%$ и $15 \%$ соответственно, по сравнению с контрольными показателями (табл.).

Активность сукцинатдегидрогеназы в суспензии митохондрий гепатоцитов подопытных крыс обеих линий после воздействия ПНГ, не отличалась от такового показателя контрольных животных, тогда как активность цитохромоксидазы в суспензии митохондрий гепатоцитов подопытных животных линии Wistar и SHR возросла, соответственно, на 14\% и 40\% $(\mathrm{P}<0,05)$ (рис. 2$)$.

\section{Обсуждение}

После воздействия ПНГ в паренхиме печени крыс линии Wistar отмечали более выраженные морфометрические изменения, чем в печени подопытных крыс линии SHR. В печени подопытных животных обеих линий выявлено увеличение размеров гепатоцитов и их ядер, количества двуядерных клеток и ядрышек в ядрах, уменьшение расстояния между ядрами смежных гепатоцитов. Гипертрофия гепатоцитов, их ядер и увеличение ядерно-цитоплазматического соотношения свидетельствует, прежде всего, о повышении их функциональной активности. Увеличение размеров гепатоцитов может быть показателем активации внутриклеточных пластических процессов, повышающих энергетические возможности клеток. Такие изменения также могут указывать на подготовку клетки к митозу и связанную с ним интенсификацию синтеза нуклеиновых кислот, белков и т. д. Увеличение плоидности гепатоцитов может свидетельствовать об активации процессов физиологической регенерации (Duncan et al., 2010).

К основным функциям ядрышек относят синтез рРНК, участвующей в образовании субъединицы рибосом. Полагают, что увеличение количества ядрышек может свидетельствовать о повышении белоксинтетической активности клеток, а их гиперплазия один из признаков активации физиологической регенерации гепатоцитов на внутриклеточном уровне (Boisvert et al., 2007). Для пе- чени всех млекопитающих характерно наличие двуядерных гепатоцитов, количество которых изменяется на протяжении жизни. У взрослых животных и человека двуядерные гепатоциты встречаются постоянно, но их процент по отношению к общему количеству клеток может варьировать.
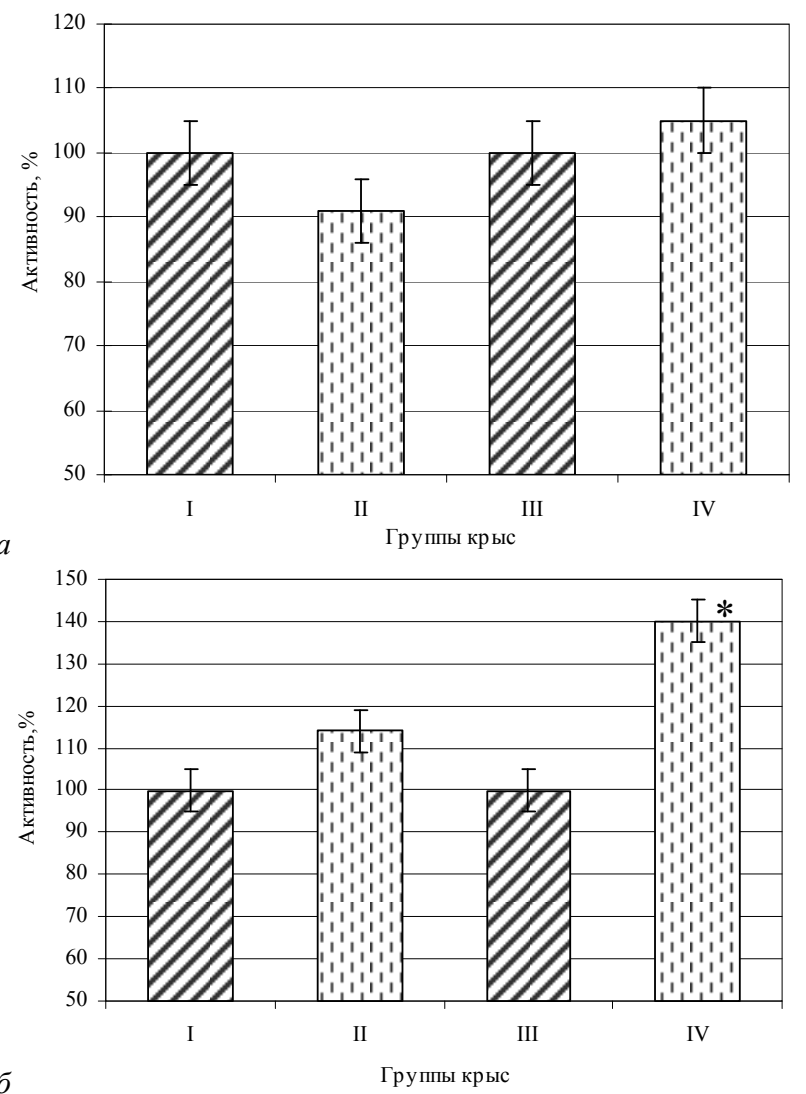

Рис. 2. Активность сукцинатдегидрогеназы ( $a$ ) и цитохромоксидазы (б) в суспензии митохондрий гепатоцитов контрольных и подопытных крыс: * $-\mathrm{P}<0,05$ по сравнению с контролем;

I и III - контрольные крысы линии Wistar и SHR соответственно, II и IV - крысы линии Wistar и SHR после воздействия прерывистой нормобарической гипоксии 
Большинство исследователей склонны считать, что образование двуядерных гепатоцитов из одноядерных в процессе регенерации представляет собой резерв полиплоидизации, которая является эквивалентом клеточному размножению (Duncan et al., 2010; Romanova and Malyshev, 2011).

Уменьшение расстояния между ядрами смежных гепатоцитов может указывать на их более плотное расположение и снижение количества межклеточной соединительной ткани, что является характерным признаком активации процессов регенерации ткани.

Под воздействием ПНГ у крыс как линии Wistar, так и линии SHR (в большей степени) повышается энергетический потенциал митохондрий гепатоцитов, что выражается в возрастании активности цитохромоксидазы - фермента цикла Кребса. Ферменты сукцинатдегидрогеназа и цитохромоксидаза непосредственно участвуют в метаболизме кислорода и синтезе АТФ. Повышение их активности свидетельствует о большей сопряженности субстратного окисления и фосфорилирования, что приводит к увеличению энергетического потенциала в ткани (Ivanskaya and Antoneeva, 2004).

Положительное влияние прерывистой нормобарической гипоксии саногенного уровня на функциональную активность печени выявили и другие исследователи. После воздействия гипоксическими газовыми смесями (10\% кислорода в азоте) в режиме 5 мин. деоксигенация, 5 мин. реоксигенация в течение 2 часов ежедневно на протяжении 10 дней активизировались пластические процессы в печени крыс: возросло количество митохондрий, пероксисом, мембран эндоплазматического ретикулума, лизосомных и липофусциновых образований. Выявлено также гипертрофию ядер гепатоцитов, гиперплазию агранулярного эндоплазматического ретикулума, полнокровие синусоидов (Lebkova et al., 1999). После воздействия дозированной гипоксии отмечены: улучшение кровенаполнения печени, активация микросомального окисления в гепатоцитах, стабилизация клеточных мембран, нормализация активности аминотрансфераз (Kurhaluk et al., 2013). При исследовании действия гипоксической газовой смеси Michael et al. (2003) наблюдали усиление экспрессии индуцируемых гипоксией транскрипционных факторов HIF-1 $\alpha$ и HIF-2 $\alpha$ в печени. При краткосрочном периодическом воздействии гипоксии происходит активация антиоксидантной системы, повышающей защиту клеточных мембран гепатоцитов (Arkhipenko et al., 2005).

\section{Выводы}

Результаты наших исследований свидетельствуют о том, что 28-суточная прерывистая нормобарическая гипоксия саногенного уровня активирует процессы физиологической регенерации и функциональной активности паренхимы печени. Об этом свидетельствует увеличение размеров гепатоцитов и их ядер, количества двуядерных клеток и ядрышек в ядрах, уменьшение расстояния между ядрами смежных гепатоцитов, а также возрастание активности цитохромоксидазы в суспензии митохондрий. Однако в паренхиме печени крыс линии Wistar данные морфофункциональные изменения были выражены в болышей степени, чем в печени подопытных крыс линии SHR. Таким образом, дозированная нормобарическая гипоксия оказывает однонаправленный, стимулирующий эффект на морфофункциональную активность гепатоцитов, но степень выраженности данного эффекта у крыс разных линий не одинакова. Полученные данные могут не только иметь теоретическое значение, но и представлять определенный практический интерес при использовании прерывистой нормобарической гипоксии в лечебных и оздоровительных целях у больных с нарушением функций печени.

\section{References}

Arkhipenko, Y., Sazontova, T., \& Zhukova, A. (2005). Periodic hypoxia and hyperoxia improves resistance of membrane structures in heart, liver and brain. Bulletin of Experimental Biology and Medicine, 140(3), 278-281.
Aron-Wisnewsky, J., Minville, C., Tordjman, J., Lévy, P., Bouillot, J. L., Basdevant, A., Bedossa, P., Clément, K., \& Pépin, J. L. (2012). Chronic intermittent hypoxia is a major trigger for non-alcoholic fatty liver disease in morbid obese. Journal of Hepatology, 56(1), 225-233.

Berezovskiy, V. A. (2012). Prirodnaya i instrumentalnaya oroterapiya [Natural and instrumental orotherapy]. Zaslavskiy A. Y., Donetsk (in Russian).

Berezovs'ky̆̌, V. I., Ianko, R. V., Litovka, I. H., Chaka, O. H., \& Zamors'ka, T. M. (2012). Dosed normobaric hypoxia as a non-medication approach of stimulation of physiological regeneration of liver parenchyma. Fiziolohichnyi Zhurnal, 58(3), 43-49.

Boisvert, F., Konningsbruggen, S., Navascues, J., \& Lamond, A. (2007). The multifunctional nucleolus. Nature Reviews Molecular Cell Biology, $8(7), 574-585$.

Chizhov, A. J., \& Billo, E. E. (2007). Gipoksicheskaja stimuljacija nespecificheskoj rezistentnosti organizma - metod povyshenija ustojchivosti k neblagoprijatnym jekologicheskim faktoram [Hypoxic stimulation of nonspecific resistance of the organism - a method of increasing resistance to unfavorable environmental factors]. Vestnik Rossijskogo Universiteta Druzhby Narodov, 6, 324-329 (in Russian).

da Rosa, D. P., Forgiarini, L. F., Baronio, D., Feijó, C. A., Martinez, D., \& Marroni, N. P. (2012). Simulating sleep apnea by exposure to intermittent hypoxia induces inflammation in the lung and liver. Mediators of Inflammation, 879419.

Dasgupta, P. (2016). Climate sensitive adaptation in health. Springer, India.

Duncan, A. W., Taylor, M. H., Hickey, R. D., Hanlon Newell, A. E., Lenzi, M. L., Olson, S. B., Finegold, M. J., \& Grompe M. (2010). The ploidy conveyor of mature hepatocytes as a source of genetic variation. Nature, 467(7316), 707-710.

Feng, S. Z., Tian, J. L., Zhang, Q., Wang, H., Sun, N., Zhang, Y., \& Chen, B. Y. (2011). An experimental research on chronic intermittent hypoxia leading to liver injury. Sleep and Breathing, 15(3), 493-502.

Ivanskaja, N. N., \& Antoneeva, I. I. (2004). Aktivnost' sukcinatdegidrogenazy i citohromoksidazi v pecheni krys pri ostroj cirkuljatornoj gipoksii [The activity of succinate dehydrogenase and cytochrome oxidase in the liver of rats with acute circulatory hypoxia]. Fundamental'nye Issledovanija, 4, 67-68 (in Russian).

Karash, J. M., Strelkov, R. B., \& Chizhov, A. J. (1988). Normobaricheskaja gipoksija $\mathrm{v}$ lechenii, profilaktike i reabilitacii [Normobaric hypoxia in treatment, prevention and rehabilitation]. Moscow (in Russian).

Korzhevskij, D. J., \& Giljarov, A. V. (2010). Osnovy gistologicheskoj tehniki [Fundamentals of histological technique]. SpecLit, SanktPeterburg (in Russian).

Krivchenkova, R. S. (1977). Opredelenie aktivnosti sukcinatdegidrogenazy v suspenzii mitohondrij [Determination of the activity of succinate dehydrogenase in a mitochondrial suspension]. Sovremennye Metody $\mathrm{v}$ Biohimiii. Medicina, Moscow, 4446 (in Russian).

Kurhaluk, N., Tkachenko, H., \& Nosar, V. (2013). The effects of intermittent hypoxia training on mitochondrial oxygen consumption in rats exposed to skeletal unloading. Annals of Clinical and Laboratory Science, 43(1), 54-63.

Lebkova, N. P., Chizhov, A. J., \& Bobkov, J. I. (1999). Adaptacionnye vnutrikletochnye mehanizmy reguljacii jenergeticheskogo gomeostaza pri preryvistoj normobaricheskoj gipoksii [Adaptive intracellular mechanisms of regulation of energy homeostasis with intermittent normobaric hypoxia]. Rossī̌skii Fiziologicheskiı̆ Zhurnal imeni I. M. Sechenova, 85(3), 403-411 (in Russian).

Mekjavic, I. B., Debevec, T., Amon, M., Keramidas, M. E., \& Kounalakis, S. N. (2012). Intermittent normobaric hypoxic exposures at rest: Effects on performance in normoxia and hypoxia. Aviation, Space and Environmental Medicine, 83(10), 942-950.

Michael, S. W., Jan, S. J., Christian, R., Charlotte, K. S., \& Jan, H. H. (2003). Widespread hypoxia-inducible expression of HIF-2a in distinct cell populations of different organs. FASEB Journal: Official Publication of the Federation of American Societies for Experimental Biology, 17(2), 271-273.

Nikonenko, A. G. (2013). Vvedenie v kolichestvennuju gistologiju [Introduction to quantitative histology]. Kniga-Pljus, Kiev (in Russian).

Romanova, L. P., \& Malyshev, I. I. (2011). Rol' dvujadernyh gepatocitov v regeneracii pecheni posle mehanicheskoj travmy $\mathrm{v}$ rannem ontogeneze $\mathrm{u}$ krys [Role of binuclear hepatocytes in liver regeneration after mechanical trauma in early ontogenesis in rats]. Vestnik Chuvashskogo Universiteta, 3, 398-402 (in Russian).

Rui, L. (2014). Energy metabolism in the liver. Comprehensive Physiology, $4(1), 177-197$.

Savransky, V., Nanayakkara, A., Vivero, A., Li, J., Bevans, S., Smith, P. L., Torbenson, M. S., \& Polotsky, V. Y. (2007). Chronic intermittent hypoxia predisposes to liver injury. Hepatology, 45(4), 1007-1013.

Schega, L., Peter, B., Brigadski, T., Leßmann, V., Isermann, B., Hamacher, D., \& Törpel, A. (2016). Effect of intermittent normobaric hypoxia on 
aerobic capacity and cognitive function in older people. Find, Browse, and Follow Biomedical Journals, 19(11), 941-945.

Serebrovskaya, T. V., \& Xi, L. (2015). Intermittent hypoxia in childhood: The harmful consequences versus potential benefits of therapeutic uses. Frontiers in Pediatrics, 19(3), 44.

Serebrovskaya, T. V., \& Xi, L. (2016). Intermittent hypoxia training as nonpharmacologic therapy for cardiovascular diseases: Practical analysis on methods and equipment. Experimental Biology and Medicine (Maywood), 241(15), 1708-1723.

Simoes, R. R., Dutra, A. L., Finamor, I. A., Saccal, E. M., Pavanato, M. A., Llesuy, S. F., Portela, L. O., \& Zanehet, E. M. (2013). The effect of intermittent hypoxic training under oxidative stress parameters in Wistar rats fed on standard and high fat diet. Caderno de Pesquisa, Serie Biologia, 25(2), 12-23.
Siques, P., Brito, J., Naveas, N., Pulido, R., De la Cruz, J. J., Mamani, M., \& León-Velarde, F. (2014). Plasma and liver lipid profiles in rats exposed to chronic hypobaric hypoxia: Changes in metabolic pathways. High Altitude Medicine and Biology, 15(3), 388-395.

Sirotinin, N. N. (1949) Gipoksija i ee znachenie v patologii [Hypoxia and its importance in pathology]. Gipoksija, AN USSR, Kiev, 19-27 (in Russian).

Tian, Y., Liu, Y., Wang, S., Dong, Y., Su, T., Ma, H., \& Zhang, Y. (2016). Antidiabetes effect of chronic intermittent hypobaric hypoxia through improving liver insulin resistance in diabetic rats. Life Sciences, 150(1), 1-7.

Yanko, R. V. (2011). Physiological regeneration and functional activity of hepatocytes at normobaric hypoxia. International Journal of Physiology and Pathophysiology, 2(1), 35-42. 